\title{
EDITOR'S FOCUS
}
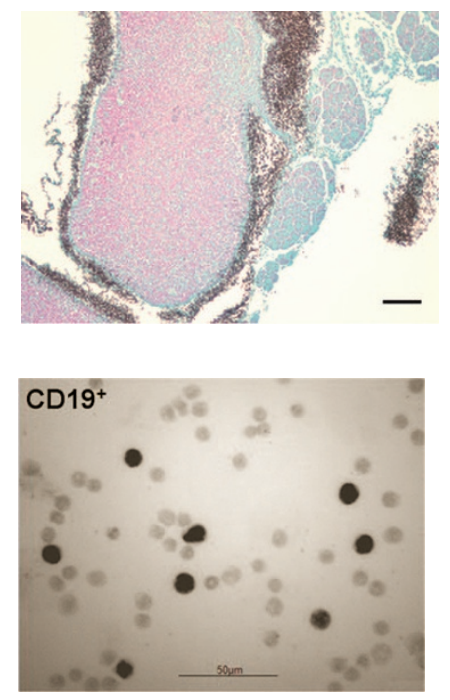

B-cell precursor acute lymphoblastic leukemic mononuclear cells reveals the $\mathrm{CD} 19^{-}$small fraction to be non-proliferative while $\mathrm{CD} 19^{+}$major fraction was proliferative explaining differential sensitivity to anti-proliferation based chemotherapy.

See page 194

Disseminated infection by candida albicans was established in neonatal mice providing a venue to examine the neonatal host system.

See page 189

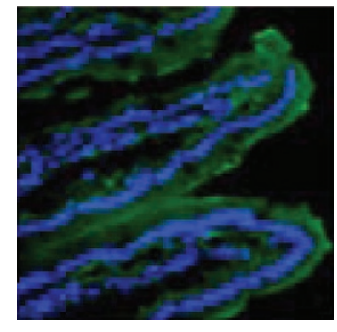

Intermittent pulse ingestion of probiotics in rats induces mucosal intestinal epithelial cell protective Muc3 gene expression.
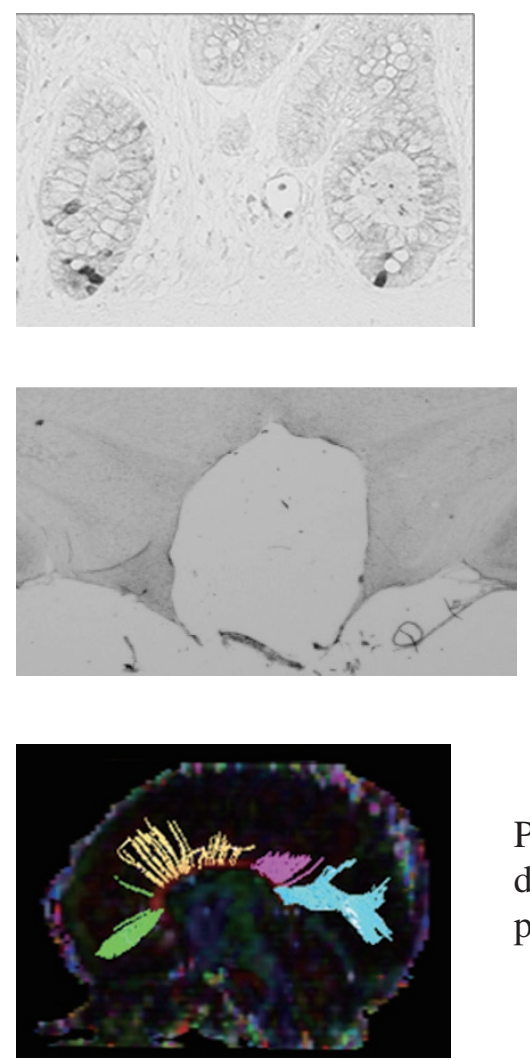

See page 206

Changes in Paneth cell morphology and alpha-defensin 5 is location and phase specific in preterm infants with necrotizing enterocolitis.

See page 217

The combined medial hypothalamic lesioned rodent model best mimicked the complex metabolic abnormalities observed in obese craniopharyngioma patients thereby providing a foundation for future pharmacological approaches.

See page 230

Preterm infants without apparent white matter lesions exhibit affected development of the posterior corpus callosum depending on the degree of prematurity. 